\title{
Hubungan Riwayat Keluarga dan Gaya Hidup dengan Hipertensi pada Lansia di Puskesmas Kuta Alam Banda Aceh
}

\author{
Relationship History of Family and Lifestyle With Hypertension in Elderly \\ Natural Health in Kuta Banda Aceh
}

Taslima ${ }^{1}$, Asmaul Husna*2

\author{
${ }^{1}$ Prodi D-III Kebidanan Fakultas Ilmu Kesehatan Universitas Ubudiyah Indonesia, Banda Aceh \\ ${ }^{2}$ Program Studi D-IV Bidan Pendidik Fakultas Ilmu Kesehatan Universitas Ubudiyah Indonesia, Banda Aceh \\ *Korespondensi Penulis : asmaul.husna@uui.ac.id
}

\begin{abstract}
Abstrak
Hipertensi merupakan resiko morbiditas dan mortalitas prematur, yang meningkat sesuai dengan peningkatan sistolik dan diastolic Data hasil studi pendahuluan yang peneliti lakukan melalui wawancara terhadap 10 lansia yang berkunjung ke Puskesmas Kuta Alam untuk berobat hipertensi, 7 dari 10 lansia mengemukakan mereka kurang mengetahui hal-hal yang berhubungan dengan hipertensi. Untuk mengetahui dan mempelajari hubungan riwayat keluarga dan gaya hidup dengan hipertensi pada lansia di Puskesmas Kuta Alam Banda Aceh Tahun 2016. Penelitian ini bersifat Analitik dengan pendekatan Cross cectional.Populasi dalam penelitian ini adalah seluruh Masyarakat yang menderita Hipertensi di Puskemas Kuta Alam Kota Banda Aceh Tahun 2016 sebanyak 68 orang. pengambilan sampel menggunakan acidenntal sampling dengan jumlah sampel 68 orang Penelitian ini dilakukan pada tanggal 01 /13 Juni 2016 Pengumpulan data dilakukan dengan menyebarkan kuesioner. Kemudian di uji statistik mengunakan. Hasil penelitian bahwa dari 68 responden yang ada riwayat keluarga sebanyak 36 responden diantaranya ibu yang mengalami hipertensi dengan kategori berat sebanyak 15 (41,7\%), $p$ value 0,003. gaya hidup baik sebanyak 39 responden diantaranya ibu yang mengalami hipertensi dengan kategori berat sebanyak 5 (12,8\%), $p$ value 0,027 . Ada hubungan antara riwayat keluarga, dan gaya hidup dengan dengan kejadian hipertensi pada lansia. Bagi petugas kesehatan diharapkan dapat memberikan informasi tentang hipertensi kepada masyarakat untuk meningkatkan pengetahuan hipertensi sehingga angka kejadian hipertensi menurun.
\end{abstract}

Kata Kunci: Hipertensi, Lansia

\section{Abstract}

Hypertension is a risk of morbidity and mortality prematurely, which increases with an increase in systolic and diastolic Data from preliminary studies that researchers do through interviews with 10 elderly people who visited the health center of Kuta Alam for treatment of hypertension, 7 out of 10 elderly people said they are less aware of -things associated with hypertension. To identify and study the relationship between family history and lifestyle with hypertension in the elderly in Puskesmas Kuta Alam Banda Aceh Year 2016. This research is an analytic approach to Cross cectional. Populasi in this study were all suffering from Hypertension Society in Kuta Alam Puskemas Banda Aceh 2016 as many as 68 people. acidenntal sampling using sampling with a sample of 68 research was conducted in date 01 s/d 13 June 2016. Data was collected by distributing questionnaires. Then tested using Chi- 
square statistics. The results of the 68 respondents that there is a family history of a total of 36 respondents among women who experienced hypertension with weight categories of 15 (41.7\%), p value 0,003. good life style as much as 39 respondents among women who experienced hypertension with severe category $5(12.8 \%), p$ value 0.027. There is a relationship between family history, and lifestyle with the incidence of hypertension in the elderly. Expected hopefully with the research I have done this can provide new knowledge and insight that the respondent had hypertension.

Keywords: Hypertension, Elderly

\section{PENDAHULUAN}

Hipertensi salah satu penyakit degeneratif yang banyak terjadi dan mempunyai tingkat mortalitas yang cukup tinggi serta mempengaruhi kualitas hidup dan produktifitas seseorang. Hipertensi sering diberi gelar the silent killer karena penyakit ini merupakan pembunuh tersembunyi dan pada umumnya pasien tidak mengetahui bahwa mereka menderita penyakit hipertensi sebelum memeriksakan tekanan darahnya.Selain itu penderita hipertensi umumnya tidak mengalami suatu tanda atau gejala sebelum terjadi komplikasi.Seseorang dikatakan hipertensi apabila tekanan darah sistolik (TDS) > $140 \mathrm{mmHg}$ dan / atau tekanan darah diastolik (TDD) > $90 \mathrm{mmHg}$ (Bustan, 2007).

Penyebab utama kematian pada lanjut usia adalah penyakit jantung, dan kanker. Penyakit jantung adalah penyebab utama kematian pada lanjut usia. Kelainan jantung yang umum adalah hipertensi dan penyakit arteri koroner.Hipertensi di diagnosis saat pengukuran berulang tekanan darah sisitolik $140 \mathrm{mmHg}$ atau lebih dan diastolik $90 \mathrm{mmHg}$ atau lebih (Bustan, 2007).

Hipertensi merupakan resiko morbiditas dan mortalitas prematur, yang meningkat sesuai dengan peningkatan sistolik dan diastolik. Sekitar $20 \%$ populasi dewasa mengalami hipertensi, lebih dari $90 \%$ diantaranya mengalami hipertensi esensial (primer), dimana tidak dapat ditentukan penyebab medis nya (Brunner dan Suddarth, 2008).

Banyak faktor yang berperan untuk terjadinya hipertensi meliputi risiko yang tidak dapat dikendalikan (mayor) dan faktor risiko yang dapat dikendalikan (minor). Faktor risiko yang tidak dapat dikendalikan (mayor) seperti keturunan, jenis kelamin, ras dan usia. Sedangkan faktor risiko yang dapat dikendalikan (minor) yaitu obesitas, kurang olah raga atau aktivitas, merokok, minum kopi, sensitivitas natrium, kadar kalium rendah, alkoholisme, stress, pekerjaan, pendidikan dan pola makan (Bustan, 2007). 
Menurut Agoes (2011), Semakin bertambah umur seseorang semakin banyak pula penyakit yang muncul dan sering diderita khususnya pada lansia atau lanjut usia. Pada usia lanjut akan terjadi berbagai kemunduran pada organ tubuh, oleh sebab itu para lansia mudah sekali terkena penyakit seperti hipertensi. Hipertensi atau penyakit "darah tinggi" merupakan kondisi ketika seseorang mengalami kenaikan tekanan darah baik secara lambat atau mendadak. Diagnosis hipertensi ditegakkan jika tekanan darah sistol seseorang menetap pada $140 \mathrm{mmHg}$ atau lebih sedangkan nilai tekanan darah yang ideal menurut Joint National Commite (JNC) adalah 120/80 mmHg.

Salah satu penyebab kejadian hipertensi adalah gaya hidup yang kurang sehat. Gaya hidup dapat diklasifikasikan menjadi beberapa komponen yang berkaitan dengan kejadian hipertensi yaitu terdiri dari merokok, merawat berat badan tetap ideal, aktif beraktivitas dan minum alkohol. Hal-hal tersebut dapat menyebabkan terjadinya hipertensi dimana merokok dapat merusak jantung dan sirkulasi darah dan meningkatkan resiko penyakit jantung dan stroke, merawat badan tetap ideal yaitu aktif beraktivitas dapat melindungi dari penyakit hipertensi, selain itu berolahraga secara teratur dapat membantu menurunkan tekanan darah dan memperbesar penurunan berat badan dan batasi minum alkohol karena apabila seseorang minum alkohol berlebihan tidak hanya meningkatkan tekanan darah tetapi juga menaikkan berat badan. Selain itu, mengkonsumsi alkohol berlebih dapat menyebabkan resistensi pada terapi antihipertensi dan berisiko terjadinya beberapa penyakit lain seperti stroke dan jantung (Bustan, 2007).

Hasil Riset Kesehatan Dasar (Riskesdas) pada tahun 2007 menyebutkan bahwa penyakit stroke menjadi penyebab kematian terbanyak $15,4 \%$, hipertensi $6,8 \%$, penyakit jantung iskemik 5,1\%, dan penyakit jantung 4,6\% (Wiryowidagdo dalam Yenni, 2009). Hipertensi menjadi masalah kesehatan masyarakat yang serius, karena jika tidak terkendali akan berkembang dan menimbulkan komplikasi yang berbahaya, khususnya bagi usia lanjut. Akibatnya bisa fatal karena sering timbul komplikasi, misalnya kebutaan, gagal ginjal, penyakit jantung, otak/stroke (perdarahan otak) (Lubis, 2009).

Hipertensi pada lanjut usia sebagian besar merupakan Hipertensi Sistolik Terisolasi (HST), meningkatnya tekanan sistolik menyebabkan besarnya kemungkinan timbulnya kejadian stroke dan infark myocard bahkan walaupun tekanan diastoliknya dalam batas normal (isolated systolic hypertension). Isolated systolic hypertension adalah bentuk 
hipertensi yang paling sering terjadi pada lansia dan merupakan faktor risiko morbiditas dan mortalitas untuk orang lanjut usia (Kuswardhani, 2007).

Prevalensi HST berturut-turut 7\% (Usia 60-69), 11\% (Usia 70-79), 18\% (Usia 80-89), dan diatas 90 tahun. HST lebih sering ditemukan pada perempuan dari pada laki-laki. Pada penelitian di Rotterdam, Belanda ditemukan: dari 7983 penduduk berusia diatas 55 tahun, prevalensihipertensi $(160 / 95 \mathrm{mmHg})$ meningkat sesuai dengan umur, dimana perempuan (39\%) lebih tinggi dibandingkan laki-laki (31\%). Sedangkan pada penelitian yang dilakukan di Asia (Taiwán) menunjukkan hasil bahwa prevalensi hipertensi sebesar 60,4\% (laki-laki $59,1 \%$ dan perempuan $61,9 \%$ ), yang sebelumnya telah terdiagnosis hipertensi adalah $31,1 \%$ (laki-laki 29,4\% dan perempuan 33,1\%), hipertensi yang baru terdiagnosis adalah 29,3\% (laki-laki 29,7\% dan perempuan 28,8\%), dimana ditemukan adanya riwayat keluarga dengan hipertensi dan tingginya indeks masa tubuh merupakan faktor risiko hipertensi (Kuswardhani, 2007).

Di Aceh prevalensi hipertensi tercatat sebesar 12,6\% (Riskesdas, 2010). Hasil studi Dinas Kesehatan Provinsi Aceh menyatakan bahwa hipertensi menempati urutan ke empat penyakit yang banyak diderita oleh masyarakat Aceh dengan jumlah kasus sekitar 3.474 kasus (Dinkes Provinsi Aceh, 2015).

Berdasarkan laporan yang peneliti peroleh dari Dinas Kesehatan, Peningkatan pertumbuhan penduduk lansia di Indonesia, mulai dirasakan sejak tahun 2000 yaitu jumlah lansia 14,4 juta orang dengan peningkatan 7,18\% dengan usia harapan hidup 64,5 tahun. Pada tahun 2006 jumlah lansia 19 juta orang dengan peningkatan sebesar 8,9\% dengan usia harapan hidup 66,2 tahun. Tahun 2010 penduduk lansia diperkirakan sebanyak 23,9 juta orang dengan peningkatan 9,7\% dengan usia harapan hidup 67,4 tahun. Pertambahan penduduk lansia inidisebabkan oleh semakin membaiknya pelayanan kesehatan dan meningkatnya usia harapan hidup orang Indonesia. Lansia perdesaan perlu mendapatkan perhatian karena diperkirakan 60\% lansia tinggal di pedesaan. Lansia di pedesaan sangat minim aksesnya terhadap fasilitas pelayanan kesehatan dan prilaku hidup sehat. Provinsi Aceh tahun 2014 cakupan pelayanan kesehatan usila 124,275 (48,9\%).

Berdasarkan data lansia yang penulis dapatkan dari Puskesmas Kuta Alam Banda Aceh, yang berkunjung dari bulan Januari 2016 sampai dengan Maret 2016 sebanyak 145 orang. Adapun yang mengalami hipertensi sebanyak 68 orang. 38 orang perempuan dan 30 orang laki-laki (Data Puskesmas Puskesmas Kuta Alam). 
Data hasil studi pendahuluan yang peneliti lakukan melalui wawancara terhadap 10 lansia yang berkunjung ke Puskesmas Kuta Alam untuk berobat hipertensi, 7 dari 10 lansia mengemukakan mereka kurang mengetahui hal-hal yang berhubungan dengan hipertensi, kategori lansia mengemukakan bahwa tekanan darahnya selalu naik turun, dan untuk mengatasi hal tersebut lansia melakukan pantangan makanan sesuai ajuran dokter, untuk mengontrol tekanan darahnya. Hipertensi yang terjadi pada lansia disebabkan oleh riwayat keluarga dan pola makan.

Berdasarkan data di atas, peneliti tertarik untuk melakukan penelitian lebih mendalam tentang "Hubungan Riwayat Keluarga Dan Gaya Hidup Dengan Hipertensi Pada Lansia Di Puskesmas Kuta Alam Banda Aceh Tahun 2016.”

\section{METODE PENELITIAN}

Jenis penelitian ini adalah penelitian yang bersifat analitik dengan menggunakan desain cross sectional yaitu variabel dependen dan variabel independen di lakukan pada waktu yang sama (Notoatmodjo, 2010).

Dalam penelitian ini penulis ingin melihat hubungan keluarga dan gaya hidup dengan hipertensi pada lansia di Puskesmas Kuta Alam Banda Aceh. Penelitian ini telah dilaksanakan di Puskesmas Kuta Alam Banda Aceh. Penelitian ini mulai dilaksanakan dari bulan Februari s/d Agustus 2016 pembagian kuesioner dari tanggal 01 Juni s/d 13 Juni 2016. Sampel pada penelitian ini adalah semua lansia yang mengalami hipertensi di Puskesmas Kuta Alam Kota Banda Aceh tahun 2016.Pengambilan sampel dilakukan dengan menggunakan total sampling sampling sebanyak 68 orang.

\section{HASIL DAN PEMBAHASAN}

Tabel 1. Distribusi Frekuensi Hipertensi Pada Lansia di Puskesmas Kuta Alam Banda Aceh Tahun 2016

\begin{tabular}{|c|c|c|c|}
\hline No & Hipertensi & $\begin{array}{l}\text { Frekuensi } \\
\text { (f) }\end{array}$ & $\begin{array}{c}\text { Persentase } \\
(\%)\end{array}$ \\
\hline 1 & Berat & 17 & 25 \\
\hline 2 & Sedang & 30 & 44,1 \\
\hline \multirow[t]{2}{*}{3} & Ringan & 21 & 30,9 \\
\hline & Total & 68 & 100 \\
\hline
\end{tabular}


Berdasarkan tabel 1 dapat dilihat bahwa dari 68 responden yang mengalami hipertensi sedang yaitu sebanyak 30 responden $(44,1 \%)$.

Tabel 2. Distribusi Frekuensi Riwayat Keluarga Pada Lansia Di Puskesmas Kuta Alam Banda Aceh Tahun 2016

\begin{tabular}{clcc}
\hline No & Riwayat Keluarga & $\begin{array}{c}\text { Frekuensi } \\
(\mathbf{f})\end{array}$ & $\begin{array}{c}\text { Persentase } \\
(\mathbf{\%})\end{array}$ \\
\hline 1 & Ada & 36 & 52,9 \\
2 & Tidak Ada & 32 & 47,1 \\
\hline \multicolumn{2}{c}{ Total } & $\mathbf{6 8}$ & $\mathbf{1 0 0}$ \\
\hline
\end{tabular}

Berdasarkan tabel 2 dapat dilihat bahwa dari 68 responden yang riwayat keluarga mengalami hipertensi yaitu sebanyak 36 responden $(52,9 \%)$.

Tabel 3. Distribusi Frekuensi Gaya Hidup Pada Lansia Di Puskesmas Kuta Alam Banda Aceh Tahun 2016

\begin{tabular}{clcc}
\hline No & Gaya Hidup & $\begin{array}{c}\text { Frekuensi } \\
(\mathbf{f})\end{array}$ & $\begin{array}{c}\text { Persentase } \\
(\mathbf{\%})\end{array}$ \\
\hline 1 & Baik & 39 & 57,4 \\
2 & Kurang Baik & 29 & 42,6 \\
\hline Total & $\mathbf{6 8}$ & $\mathbf{1 0 0}$ \\
\hline
\end{tabular}

Berdasarkan tabel 3 dapat dilihat bahwa dari 68 responden yang gaya hidup baik yaitu sebanyak 29 responden $(42,9,9 \%)$.

Tabel 4. Hubungan Riwayat Keluarga dengan Hipertensi Pada Lansia Di Puskesmas Kuta Alam Banda Aceh Tahun 2016

\begin{tabular}{|c|c|c|c|c|c|c|c|c|c|c|}
\hline \multirow[t]{3}{*}{ No } & \multirow{3}{*}{$\begin{array}{l}\text { Riwayat } \\
\text { Keluarga }\end{array}$} & \multicolumn{6}{|c|}{ Hipertensi } & \multirow{2}{*}{\multicolumn{2}{|c|}{ Total }} & \multirow{3}{*}{$\begin{array}{c}\text { p- } \\
\text { value }\end{array}$} \\
\hline & & \multicolumn{2}{|c|}{ Berat } & \multicolumn{2}{|c|}{ Sedang } & \multicolumn{2}{|c|}{ Ringan } & & & \\
\hline & & $\mathbf{f}$ & $\%$ & $\mathbf{f}$ & $\%$ & $\mathbf{f}$ & $\%$ & n & $\%$ & \\
\hline 1 & Ada & 15 & 41,7 & 12 & 33,3 & 9 & 25 & 36 & 100 & \\
\hline 2 & Tidak Ada & 2 & 6,2 & 18 & 56,2 & 12 & 37,5 & 32 & 100 & 0,003 \\
\hline
\end{tabular}


Berdasarkan tabel 4 diatas dapat diketahui bahwa dari 36 responden yang ada riwayat keluarga mengalami hipertensi sedang yaitu sebanyak 12 responden $(33,3 \%)$, sedangkan dari 32 responden yang tidak ada riwayat keluarga mengalami hipertensi sedang yaitu sebanyak 18 responden $56,2 \%$.

Hasil analisis statistik menggunakan uji chi-square didapatkan p value 0,003. Sehingga dapat disimpulkan bahwa $\mathrm{p}<0,05$ yang artinya Ha diterima atau terdapat hubungan riwayat keluarga dengan hipertensi pada lansia Di Puskesmas Kuta Alam Banda Aceh Tahun 2016.

Tabel 5. Hubungan Gaya Hidup Dengan Hipertensi Pada Lansia Di Puskesmas Kuta Alam Banda Aceh Tahun 2016

\begin{tabular}{|c|c|c|c|c|c|c|c|c|c|c|}
\hline \multirow[t]{3}{*}{ No } & \multirow[t]{3}{*}{ Gaya Hidup } & \multicolumn{6}{|c|}{ Hipertensi } & \multirow{2}{*}{\multicolumn{2}{|c|}{ Total }} & \multirow{3}{*}{$\begin{array}{c}\text { p- } \\
\text { value }\end{array}$} \\
\hline & & \multicolumn{2}{|c|}{ Berat } & \multicolumn{2}{|c|}{ Sedang } & \multicolumn{2}{|c|}{ Ringan } & & & \\
\hline & & $\mathbf{f}$ & $\%$ & $\mathbf{f}$ & $\%$ & $\mathbf{f}$ & $\%$ & $\mathbf{n}$ & $\%$ & \\
\hline 1 & Baik & 5 & 12,8 & 20 & 51,3 & 14 & 35,9 & 39 & 100 & \\
\hline 2 & Kurang Baik & 12 & 41,4 & 10 & 34,5 & 7 & 24,1 & 29 & 100 & 0,027 \\
\hline
\end{tabular}

Berdasarkan tabel 5 diatas dapat diketahui bahwa dari 36 responden yang gaya hidup baik mengalami hipertensi sedang yaitu sebanyak 20 responden (51,3\%), sedangkan dari 29 responden yang gaya hidup kurang baik mengalami hipertensi sedang yaitu sebanyak 10 responden $24,5 \%$.

Hasil analisis statistik menggunakan uji chi-square didapatkan p value 0,027. Sehingga dapat disimpulkan bahwa $\mathrm{p}<0,05$ yang artinya Ha diterima atau terdapat hubungan gaya hidup dengan hipertensi pada lansia Di Puskesmas Kuta Alam Banda Aceh Tahun 2016.

\section{Pembahasan}

1. Hubungan Riwayat Keluarga Dengan Hipertensi Pada Lansia

Berdasarkan hasil penelitian tabel 4 di dapat hasil analisis statistik menggunakan uji chi-square didapatkan $p$ value 0,003. Sehingga dapat disimpulkan bahwa $\mathrm{p}<0,05$ yang artinya Ha diterima atau terdapat hubungan riwayat keluarga dengan hipertensi pada lansia Di Puskesmas Kuta Alam Banda Aceh Tahun 2016.

Hasil penelitian sama dengan penelitian yang telah dilakukan oleh Ruhamah (2013), menunjukkan bahwa dari 52 responden yang riwayat keluarga yang tidak ada 
yaitu sebanyak 34 responden $(65,4 \%)$ dengan mengalami hipertensi ringan. Hasil analisis statistik menggunakan uji Chi-square didapat nilai $\mathrm{p}$ value $=0,001(\mathrm{p} \leq 0,05)$ artinya ada hubungan antara riwayat keluaga dengan kejadian hipertensi pada lansia Puskesmas Ulee Kareng Banda Aceh Tahun 2015.

Hasil penelitian ini sejalan dengan penelitian yang telah dilakukan oleh Susanti, (2005), menunjukkan Setelah dilakukan uji statistic dengan chi-square diperoleh nilai $\mathrm{p}=$ $0,000<\alpha(0,05)$ yang artinya terdapat hubungan antara riwayat keluarga dengan kejadian hipertensi.

Riwayat keluarga mempertinggi risiko terkena penyakit hipertensi, terutama pada hipertensi primer (esensial). Tentunya faktor genetik ini juga diperngaruhi faktor-faktor lingkungan lain. Faktor genetik juga berkaitan dengan metabolisme pengaturan garam dan renin membran sel. Hipertensi cenderung merupakan penyakit keturunan.Jika seorang dari orang tua kita mempunyai hipertensi maka sepanjang hidup kita mempunyai 25\% kemungkinan mendapatkannya pula.Jika kedua orang tua kita mempunyai hipertensi, kemungkinan kita mendapatkan penyakit tersebut 60\% (Sheps, 2009).

Faktor genetik pada keluarga tertentu akan menyebabkan keluarga tersebutmemiliki risiko menderita hipertensi. Hal ini berhubungan dengan peningkatankadar natrium intraseluler dan rendahnya rasio antara kalium terhadap natrium.Penelitian yang dilakukan oleh Androgue dan Madias mengenai patogenesis kalium dan natrium pada hipertensi, menyebutkan faktor keturunan berpengaruh terhadap hipertensi primer melalui beberapa gen yang terlibat dalam regulasi vaskuler dan reabsorpsi natrium oleh ginjal (Marliani, 2007).

Menurut asumsi peneliti bahwa ada hubungan riwayat keluarga dengan hipertensi pada lansia dari hasil dilapangan lebih banyak yang riwayat keluarga yang ada mengalami hipertensi dibandingkan dengan riwayat keluarga tidak ada mengalami hipertensi, Karena Riwayat keluarga merupakan seorang akan lebih mendekati tekanan darah orang tuanya bila mereka memiliki hubungan darah, sehingga akan kemungkinan terjadi hipertensi pada dirinnya. Dari hasil di lapangan respoden yang mengalami hipertensi berat lebih banyak didapati dengan adanya riwayat keluarganya, dibandingkan dengan riwayat keluarga yang tidak ada hipertensi. 


\section{Hubungan Gaya Hidup Dengan Hipertensi Pada Lansia}

Berdasarkan hasil penelitian tabel 3 didapat hasil analisis statistik menggunakan uji chi-square didapatkan $p$ value 0,027. Sehingga dapat disimpulkan bahwa $\mathrm{p}<0,05$ yang artinya Ha diterima atau terdapat hubungan gaya hidup dengan hipertensi pada lansia Di Puskesmas Kuta Alam Banda Aceh Tahun 2016.

Hasil penelitian oleh Ruhamah (2013), menunjukkan bahwa dari 39 responden yang gaya hidup baik sebanyak 26 responden $(66,7 \%)$ dengan mengalami hipertensi ringan. Hasil analisis statistik menggunakan uji Chi-square didapat nilai p value $=0,043$ (p $\leq$ $0,05)$ artinya ada hubungan antara gaya baik dengan kejadian hipertensi pada lansia Puskesmas Ulee Kareng Banda Aceh Tahun 2015.

Hasil penelitian ini sejalan dengan penelitian yang telah dilakukan oleh (Sihombing, 2010) menunjukkan Setelah dilakukan uji statistic dengan chi-square diperoleh nilai $\mathrm{p}=$ $0,003<\alpha(0,05)$ yang artinya terdapat hubungan antara olaharaga dengan kejadian hipertensi.

Gaya hidup adalah pola hidup seseorang di dunia yang diekspresikan dalam bentuk aktivitas, minat, dan opininya. Gaya hidup yang sehat menerapkan kebiasaan yang baik dalam menciptakan hidup yang sehat dan menghindari kebiasaan yang buruk yang dapat mengganggu kesehatan serta memperhatikan faktor-faktor yang dapat mempengaruhi kesehatan seperti pola makan dan Olahrga Bustan (2007).

Menurut Dalimartha (2008), modernisasi biasanya mengubah pola hidup menjadi lebih praktis, termasuk juga soal makanan. Pada umumnya, masyarakat perkotaan cenderung memilih makanan siap saji dan mempunyai kebiasaan makanan berlebihan, kurang olahraga, merokok berlebihan, kurang istrahat. Akibat nya sejak sepuluh tahun terakhir, penyakit hipertensi banyak menyerang masyarakat, terutama yang berusia di atas 40 tahun, bahkan ada yang telah terserang mulai umur sekitar 30 tahun.

Menurut asumsi peneliti menunjukkan bahwa ada hubungan gaya hidup dengan hipertensi pada lansia, dari hasil lapangan yang didapatkan lebih banyak gaya hidup yang baik mengalami hipertensi dibandingkan dengan gaya hidup kurang baiak disebabakan Seiring berubahnya gaya hidup diperkotaan mengikuti era globalisasi, hipertensi pada lansia terus meningkat, hal ini disebabkan karena lansia malas untuk melakukan olahraga yang dapat mencegah terjadinya hipertensi seperti berjalan kaki di pagi atau sore hariA, menaiki tangga, bersepada, berternak, dan olahraga lainnya. Dengan demikian kebutuhan 
olahraga yang diperlukan oleh tubuh sangat sedikit sehingga menyebabkan terjadinya hipertensi pada lansia.

\section{KESIMPULAN}

Berdasarkan hasil penelitian dari Hubungan riwayat keluarga dan gaya hidup dengan hipertensi pada Lansia Di Puskesmas Kuta Alam Banda Aceh Tahun 2016 maka dapat disimpulkan sebagai berikut :

1. Dari 36 responden yang ada riwayat keluarga mengalami hipertensi sedang yaitu sebanyak 12 responden $(33,3 \%)$, sedangkan dari 32 responden yang tidak ada riwayat keluarga mengalami hipertensi sedang yaitu sebanyak 18 responden 56,2\%. Dari hasil uji chisquare didapatkan $p$ value 0,003. Maka dapat disimpulkan bahwa ada hubungan riwayat keluarga dengan hipertensi pada lansia Di Puskesmas Kuta Alam Banda Aceh Tahun 2016.

2. Dari 36 responden yang gaya hidup baik mengalami hipertensi sedang yaitu sebanyak 20 responden $(51,3 \%)$, sedangkan dari 29 responden yang gaya hidup kurang baik mengalami hipertensi sedang yaitu sebanyak 10 responden 24,5\%. Dari hasil uji uji chi-square didapatkan $p$ value 0,027. Maka dapat disimpulkan bahwa ada hubungan gaya hidup dengan hipertensi pada lansia Di Puskesmas Kuta Alam Banda Aceh Tahun 2016, p value 0,027. yang artinya Ha diterima.

\section{SARAN}

Bagi Institusi pendidikan dapat menjadikan hasil penilitian ini sebagai bahan masukan untuk mengembangkan ilmu pengetahuan tentang khususnya tentang masalah hipertensi pada lansia.Diharapakn Agar dapat memberikan informasi atau masukan tentang gaya hidup yang berhubungan dengan terjadinya hipertensi pada lanjut usia. Bagi petugas kesehatan diharapkan dapat memberikan informasi tentang hipertensi kepada masyarakat untuk meningkatkan pengetahuan hipertensi sehingga angka kejadian hipertensi menurun.

\section{DAFTAR PUSTAKA}

Agoes, H. A. (2011). Penyakit Diusia Tua. EGC: Jakarta.

Bustan.(2007). Epidemiologi Penyakit Tidak Menular. Rineka Cipta : Jakarta

Brunner dan Suddart. (2008)..Buku ajar keperawatan medical bedah. Jakarta : EGC 
Dalimartha.S, (2008).Care Your Self Hipertensi. Jakarta : Penebar Plus.

Dinas Kesehatan Provinsi Aceh. (2014). Profil kesehatan Provinsi Aceh.

Kuswardhani, (2007).Penatalaksanaan Hipertensi Pada Lanjut Usia. Denpasar :Bagian Penyakit Dalam FK. Unud, RSUP Sanglah Denpasar.

Kusuma, Afandi. (2009). Aditif Makanan. http:// id.Wikipedia.org/wiki/ aditif makanan., diakses 14 Maret 2015.

Lubis, (2009).Buku Ajar Ilmu Penyakit Dalam Jilid III Edisi Ketiga.Jakarta : FK UI.

Sheps, (2009), Mayo Klinik Hipertensi, Jakarta.

Udjiyanti, (2010). Keperawatan Kardiovaskuler. Jakarta : Salemba Medika.

Yenni, (2009).Faktor-faktor Yang Berhubungan Dengan Kejadian Hipertensi Pada Wanita Usia Subur di Puskesmas Umbulharjo I Yogyakarta. Karya Tulis Ilmiah. Fakultas Kesehatan Masyarakat Universitas Ahmad Dahlan 